\title{
Telenovelas, identidad y alteridad: imaginarios sociales sobre mujeres migrantes en telenovelas chilenas
}

\author{
Eduardo Gallegos Krause \\ UNIVERSIDAD DE LA FRONTERA (CHILE) \\ eduardo.gallegos@ufrontera.cl
}

\begin{abstract}
Resumen
El presente artículo caracteriza la telenovela como producto cultural en el marco de los estudios culturales y analiza la construcción de la identidad y la alteridad como proceso significacional. Para esto, propone un análisis socio-semiótico de la imagen de la telenovela y semio-discursivo del relato melodramático a fin de identificar los imaginarios sociales sobre la mujer migrante que aparecen en tres novelas chilenas. Los resultados dan cuenta de un imaginario de la mujer inmigrante asociado a: sexualización, antagonismo y victimización.

Palabras clave: Telenovela, imaginario, identidad, alteridad, mujer, migrante

\section{Resumo}

Este artigo caracteriza a telenovela como produto cultural no âmbito dos estudosculturais e analisa a construção da identidade e da alteridade como umprocesso de significação. Para este fim, propõeumaanálisesócio-semiótica da imagem da telenovela e discursiva história melodramática semio para identificar o imaginário social das mulheres migrantes que aparecemnastrês romances chilenos. Os resultados mostramumimaginário de mulheresimigrantesassociado a: sexualização, antagonismo e vitimização.

Palavras chaves: Telenovela, imaginário, identidade,alteridade, mulheres, migrant
\end{abstract}

\section{Introducción}

Según Rojas \& Silva (2016) se ha percibido por parte de la opinión pública chilena un alto flujo de migrantes con componentes de afrodescendientes o de indígenas andinos, lo que repercute en que “(...) la opinión pública nacional perciba que el país se está 'llenando' de inmigrantes..." (Rojas \& Silva, 2016: 10). 


\section{$\checkmark$ REVCOm \\ REVISTA CIENTIFICA DE LA REDCOM}

REVCOM | ISSN 2451-7836 | Año 4, \#8 | mayo de 2019 | Contribuciones | e013

En este marco los medios en general, y las teleseries en particular, tienen un rol dentro de la integración de inmigrantes en sus contenidos, como poseedores de un carácter simbólicosignificativo e interaccional que se relaciona con los intercambios sociales y la construcción de imaginarios con consecuencias en las prácticas sociales (Charaudeau, 2003; Thompson, 1998; Curran, 2002). Con lo hasta aquí expuesto, planteamos las preguntas que guían el análisis: ¿Cómo se construye la significación de la mujer migrante en las telenovelas chilenas? ¿Cuáles son los imaginarios sociales -o recursos simbólico-significativos- sobre la mujer migrante posibles de ser observados en las telenovelas?

En términos teóricos se emplea la teoría de los imaginarios sociales, su vinculación con lo significacional-simbólico y la construcción de la identidad y la alteridad. Así, los imaginarios sociales (Castoriadis, 2007; Baczko, 2005) son constructos simbólicos que conforman la construcción social de la realidad (Berger \& Luckmann, 2001) .

En términos metodológicos, y en consonancia con la descripción eminentemente significacional de los imaginarios sociales y de la construcción de la identidad y la alteridad, se presenta una caracterización del material estudiado y se propone un modelo de análisis que recoge por un lado la imagen televisiva de la telenovela (análisis de la dimensión sociosemiótica de la imagen) y por otro lado la narración melodramática ${ }^{1}$ de la teleserie (análisis de la dimensión semio-discursiva del relato melodramático).

\section{Marco teórico: imaginarios de la identidad/alteridad en las telenovelas}

Se sitúa aquí la telenovela como parte del campo cultural, referido este a la "producción institucionalizada de bienes simbólicos" (Santa Cruz, 2003: 52), donde se dan relaciones de cooperación, conflicto y resignificación, de modo que la telenovela y la cultura televisiva en general no puede ser reducida a la idea de estructura o aparato de manipulación. Valga este comentario para matizar cualquier idea de determinismo o control absoluto de las audiencias por parte de los medios (cfr. Wolf, 1987; McQuail, 2000; Mattelart\&Mattelart, 1997), para seguir más bien la tradición que nos lleva a repensar los medios en su relación con las mediaciones sociales (Martin-Barbero, 1991) y los procesos de decodificación (Hall, 1996) y re-significación que las audiencias llevan a cabo.

1A lo largo del texto se utilizan de manera casi sinonímica los conceptos de melodrama, teleserie y telenovela. Sin embargo, al hablar de melodrama acentuamos las características narrativas y actorales que serán analizadas como parte de la semiótica discursiva. Del mismo modo, al hablar de teleserie acentuamos las características visuales que serán analizadas como parte de la semiótica de la imagen. 


\section{VREVCom \\ REVISTA CIENTIFICA DE LA REDCOM}

REVCOM | ISSN 2451-7836 | Año 4, \#8 | mayo de 2019 | Contribuciones | e013

Se visualiza así la vinculación directa entre las telenovelas y los imaginarios sociales haciendo referencia a la distribución de categorías sociales, expresando ciertas ideas compartidas y reproducidas socialmente o fijando modelos de conducta que apelan a elementos identitarios y valóricos que permiten la construcción imaginaria de anhelos e intereses de los sujetos sociales (Mazziotti, 2006).

Ahora bien, el análisis que aquí se propone busca estudiar en una primera etapa el contenido significacional asociado a las mujeres migrantes sin considerar la interpretación de las audiencias, cuestión que se pretende abordar en estudios posteriores. Se considera aquí de manera preliminar un análisis de discurso del propio medio, es decir, en términos de la enunciación en que se constituyen los propios productos mediáticos, donde las telenovelas son visualizadas como parte de las narrativas culturales que imaginan y construyen lo social, y particularmente en este caso a la mujer inmigrante.

Así, en la definición eminentemente significacional de los imaginarios sociales que hasta aquí se ha esbozado, la construcción de la alteridad que opera en las telenovelas aparece como un conjunto significativo-simbólico donde se cumplen las definiciones y relaciones otorgadas a los imaginarios sociales en razón de distinción, articulación de ideas y acciones, valorizaciones colectivas, etc. Esta es la razón por la que se considera importante aquí indagar en una primera instancia la forma en que el contenido melodramático de las teleseries aborda la significación de la mujer migrante, particularmente en términos de distinción entre "nosotros" y los "otros".

Se considera así recíprocamente la construcción de la identidad y de la alteridad -esto es el Yo y el Otro- como parte de las significaciones socialmente elaboradas y que se han definido como imaginarios sociales que se (re)construyen mutuamente, donde no es posible concebir la identidad sin la existencia de la alteridad. "Solamente cuando hay otro puede uno saber quién es uno mismo" (Hall, 2010: 344). Cobra entonces relevancia el estudio de la telenovela como producción cultural en cuyo seno se significan las referencias al nosotros y a los otros, a la identidad y a la alteridad, más aún considerando el contexto chileno de una inmigración creciente y que no carece de situaciones problemáticas asociadas al racismo, sexualización de la mujer migrante, entre otras cuestiones (Tijoux \& Palominos, 2015). 


\section{$\downarrow_{\text {REVCOM }}$ \\ REVISTA CIENTIFICA DE LA REDCOM}

REVCOM | ISSN 2451-7836 | Año 4, \#8 | mayo de 2019 | Contribuciones | e013

\section{Marco metodológico: análisis socio-semiótico de la imagen de la telenovela y análisis}

\section{semio-discursivo del melodrama}

\subsection{Consideraciones formales del material analizado}

Si bien se conocen antecedentes referidos a migrantes en telenovelas chilenas (años 1998, 1999, 2001 y 2004), se trata de migrantes europeos o árabes, de manera que se ha optado aquí por analizar al inmigrante en ficciones melodramáticas de data reciente por dos razones: se presume que son respuesta a la creciente inmigración latinoamericana donde Chile ha aparecido como destino en razón a un supuesto auge socio-económico, y a que por tratarse de teleseries recientes responden a lo que Fuenzalida et. al. (2009) caracterizan como un cambio en las teleseries, que a diferencia de los año 80 y 90, están hoy por hoy abordando temas más atrevidos y controversiales, lo que dio lugar a que las teleseries aparecieran en horario nocturno.

\begin{tabular}{lllll} 
Personaje/Origen & $\begin{array}{l}\text { Teleseriel } \\
\text { Canal }\end{array}$ & $\begin{array}{l}\text { Año de } \\
\text { exhibición }\end{array}$ & Episodios & Horario \\
\hline $\begin{array}{l}\text { Úrsula. } \\
\text { Peruana }\end{array}$ & $\begin{array}{l}\text { El } \\
\text { camionero } \\
\text { TVN }\end{array}$ & $2016-2017$ & 149 & Vespertino \\
& & & & \\
\hline $\begin{array}{l}\text { María Camila. } \\
\text { Colombiana }\end{array}$ & $\begin{array}{l}\text { Preciosas } \\
\text { Canal 13 }\end{array}$ & $2016-2017$ & 93 & Nocturno \\
\hline $\begin{array}{l}\text { Rosa María. } \\
\text { Colombiana }\end{array}$ & $\begin{array}{l}\text { Te doy la } \\
\text { vida } \\
\text { Mega }\end{array}$ & & & \\
\hline
\end{tabular}

Tabla 1. Telenovelas y personajes analizados. Elaboración propia

Las tres telenovelas analizadas (Tabla 1) fueron seleccionadas en consideración de que en todas aparecen inmigrantes mujeres. Se ha optado aquí por obviar otras mujeres migrantes que aparecen en teleseries de data reciente como "Tranquilo papá" (2017-2018/MEGA) por tratarse de un personaje en una trama totalmente periférica donde un personaje representa una asesora del hogar argentina que viene al país con anhelos de fama. Tampoco se consideró la telenovela "La Colombiana" (2018/TVN) ya que se trata de una telenovela que se centra en la 
REVCOM | ISSN 2451-7836 | Año 4, \#8 | mayo de 2019 | Contribuciones | e013

problemática migrante a diferencia de los personajes seleccionados para este análisis, que se integran más bien a temáticas relativamente comunes en las telenovelas chilenas. Sin duda el caso de La Colombiana ameritaría un análisis particular, de modo que los resultados del análisis que aquí se presentan se circunscriben a las teleseries analizadas y no a todas las teleseries chilenas.

Como estrategia metodológica y en atención a la basta cantidad de material referido a cada una de las teleseries y de los personajes analizados (ver tabla 1), se tomó como corpus de análisis 60 escenas -20 para cada uno de los personajes-, las que fueron tomadas de las plataformas digitales de los propios canales de televisión (plataformas de Youtube institucionales) donde los medios almacenan parte de sus contenidos en una tendencia que vincula la televisión con otras plataformas digitales.

En este sentido, parece coherente con la perspectiva de análisis del discurso mediático melodramático considerar aquellas escenas que los propios medios han decidido articular en plataformas digitales, ya que esto da señales sobre las escenas que consideran significacionalmente más relevantes en términos de enunciación. Esta estrategia metodológica ha permitido seleccionar 20 escenas para cada personaje en cuestión, con la facilidad de poder utilizar los motores de búsqueda de los que disponen las plataformas digitales para poder abordar particularmente las escenas referidas a los personajes que aquí se analizan.

\subsection{Propuesta metodológica: Dimensión socio-semiótica y semio-discursiva}

Como propuesta metodológica consideramos dos dimensiones de análisis (Tabla 2). La primera se refiere al análisis de la imagen audiovisual entendida como un texto dinámico con referencias significacionales previas asociadas a la gestualidad e implicaciones emocionales (Fuenzalida, 2012), además de referencias narrativas y culturales que van más allá de la imagen misma.

Se caracteriza aquí la imagen en general, sea estática o en movimiento como en el caso de la telenovela, bajo el concepto general de imágenes icónicas con el fin de facilitar la práctica analítica, pues no es menos cierto que los medios de producción determinan una primera codificación de la imagen (Gubern, 1994).

Esta definición se considera pertinente y coherente, pues lo que se pretende analizar son las formas en que la imagen icónica (o imaginario icónico) es parte de una imagen mental asociada a conceptos significantes y representaciones propias de determinada cultura y época 


\section{REVCOm \\ REVISTA CIENTIFICA DE LA REDCOM}

REVCOM | ISSN 2451-7836 | Año 4, \#8 | mayo de 2019 | Contribuciones | e013

(Gubern, 1994: 19), asociada a imaginarios investidos de sentido que desembocan en formas de (re)conocimiento (Gubern, 1994: 29) que en este caso se vinculan con la alteridad migrante, de ahí que hablamos de dimensión socio-semiótica (Landowski, 1993).

\section{ANALISIS DE LA DIMENSION SOCIO- SEMIOTICA DE LA IMAGEN DE LA TELENOVELA}

\begin{tabular}{|c|c|c|}
\hline Nivel icónico & \multicolumn{2}{|c|}{ Nivel iconográfico } \\
\hline $\begin{array}{l}\text { Describe los elementos de la imagen. Da } \\
\text { cuenta de los elementos físicos (ropas, } \\
\text { cantidades, formas, colores, encuadre de la } \\
\text { imagen, etc.) }\end{array}$ & \multicolumn{2}{|c|}{$\begin{array}{l}\text { Interpreta los elementos de la imagen. Da } \\
\text { cuenta de los estados de ánimo y mentales; } \\
\text { interpreta los elementos físicos. }\end{array}$} \\
\hline \multicolumn{3}{|l|}{$\begin{array}{c}\text { ANALISIS DE LA DIMENSION SEMIO- } \\
\text { DISCURSIVA DEL RELATO } \\
\text { MELODRAMATICO }\end{array}$} \\
\hline Nivel figurativo & & $\begin{array}{l}\text { Nivel actancial- } \\
\text { narrativo }\end{array}$ \\
\hline $\begin{array}{l}\text { Identifica y describe las figuras entendidas } \\
\text { sustitución, calificación, y el o los sentidos p } \\
\text { Así mismo da cuenta de las Isotopías ente } \\
\text { de unidad de universos semióticos y recorrid }\end{array}$ & $\begin{array}{l}\text { como elementos de } \\
\text { ira un sujeto u objeto. } \\
\text { didas como principio } \\
\text { s figurativos. }\end{array}$ & $\begin{array}{l}\text { Identifica y describe } \\
\text { objetos de valor en } \\
\text { disputa entre los } \\
\text { actantes del relato, } \\
\text { entendiendo estos } \\
\text { objetos como motor } \\
\text { de significación. De } \\
\text { este modo evalúa } \\
\text { los program a s } \\
\text { narrativos, las } \\
\text { modalizaciones de } \\
\text { los actantes (poder, } \\
\text { querer, de be r, } \\
\text { saber) y caracteriza } \\
\text { a los ayudantes y } \\
\text { oponentes. }\end{array}$ \\
\hline
\end{tabular}

Tabla 2. Modelo de Análisis. Elaboración propia

Así, consideramos a la imagen como un conjunto, constituida por tres mensajes (Barthes, 1964): un mensaje icónico codificado, un mensaje icónico no codificado y un mensaje lingüístico.

La segunda dimensión de análisis se refiere al hecho ya explicitado de que la imagen está rodeada de un mensaje lingüístico (lo que los actores dicen) y que constituyen una 
REVCOM | ISSN 2451-7836 | Año 4, \#8 | mayo de 2019 | Contribuciones | e013

narración mayor que es la historia misma del melodrama. En este sentido, el modelo de análisis que proponemos considera una dimensión semio-discursiva del relato melodramático que se relaciona con el desarrollo de la semiótica narrativa en el análisis de los componentes narrativos, actanciales, de modalización, entre otros (Fontanille, 2001; 2004; 2009; Gallegos, 2015; Giroud\&Panier, 1988; Courtés, 1980; Greimás, 1973). Esta tradición de análisis semiótico del discurso tiene dentro de sus componentes una consideración a la inmanencia del texto, por lo que las categorías que se proponen a continuación como parte de los resultados no deben ser vistas como categorías a priori impuestas al corpus, sino como los componentes significacionales -y por lo tanto imaginarios- que afloraron al aplicar el modelo de análisis que aquí se ha descrito.

\section{Resultados: entre imaginario de sexualización, antagonismo y victimización}

\subsection{Sexualización y erotismo}

Dentro de las escenas analizadas referidas al personaje de Úrsula, se aprecia una exacerbación de rasgos y elementos sexuales y de voluptuosidad física, capaces de ser identificados con una significación de la imagen relacionada con la sensualidad y la sexualidad de la mujer migrante. Esto es cierto en el caso de Úrsula desde el primer momento que entra en escena, donde es grabada con un paneo vertical ascendente, apoyada sensualmente a un vehículo y donde se muestran sucesivamente unos tacos negros, sus pantorrillas, muslos y el estrecho vestido que usa (imagen 1). Posteriormente a esa escena, Úrsula le señala a Antonio que le ha traído un regalo; que es el hecho de haberse tatuado cerca de sus pechos el nombre "Antonio". Nuevamente aquí la cámara se detiene en los senos de Úrsula.

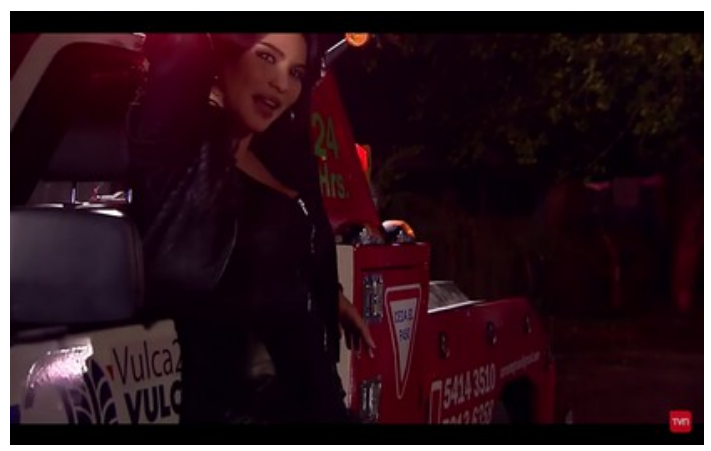

Imagen 1 


\section{ReVcom \\ REVISTA CIENTIFICA DE LA REDCOM}

REVCOM | ISSN 2451-7836 | Año 4, \#8 | mayo de 2019 | Contribuciones | e013

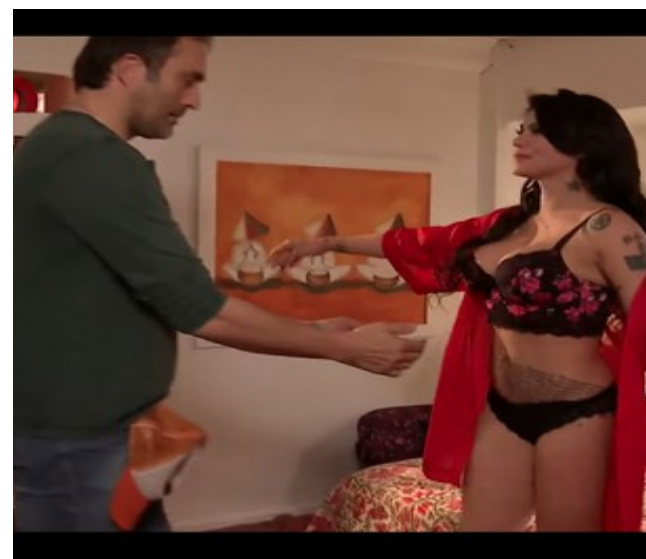

Imagen 2

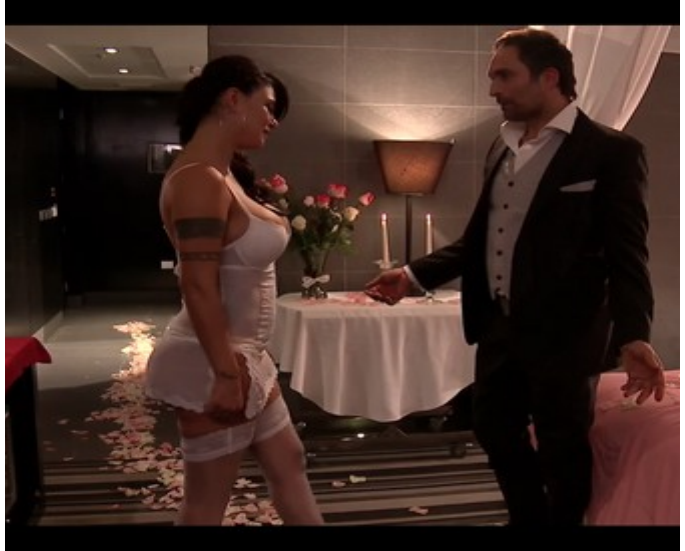

Imagen 3

ANALISIS IMAGEN 2

Nivel icónico
La apertura de la bata en la secuencia da cuenta de una suerte de entrega física y sexual de Úrsula hacia Antonio. El contrapunto entre la expresión de semidesnudez y la vestimenta de Antonio es total, dando cuenta de que se sexualiza y erotiza sólo a la mujer.

Tabla 3. Análisis imagen 1. Elaboración propia

Úrsula aparece entonces como un sujeto altamente vinculado a un imaginario erótico o sexualizado de la alteridad, e incluso como un objeto de deseo en la significación general. Es revelador que en el análisis propuesto (Tabla 3) Antonio señale "¿Es hora de los regalos?" aludiendo a la entrega físico/sexual que acometerá su pareja. La objetivación sexual de Úrsula puede verse también en la forma en que Antonio a manera de cariño se refiere a ella, llamándola generalmente "suspirito limeño", haciendo alusión al postre peruano, lo que puede ser visto como referencia metafórica en el uso del lenguaje donde el acto sexual se asocia a comer (Alarcón, 2002).

El caso de María Camila en términos de sexualización es similar, ya que aparece vestida la mayoría de las ocasiones con escotes amplios, vestidos ajustados u otros atuendos que dan cuenta del imaginario sexual con el que se significa su presencia en la telenovela, apareciendo 


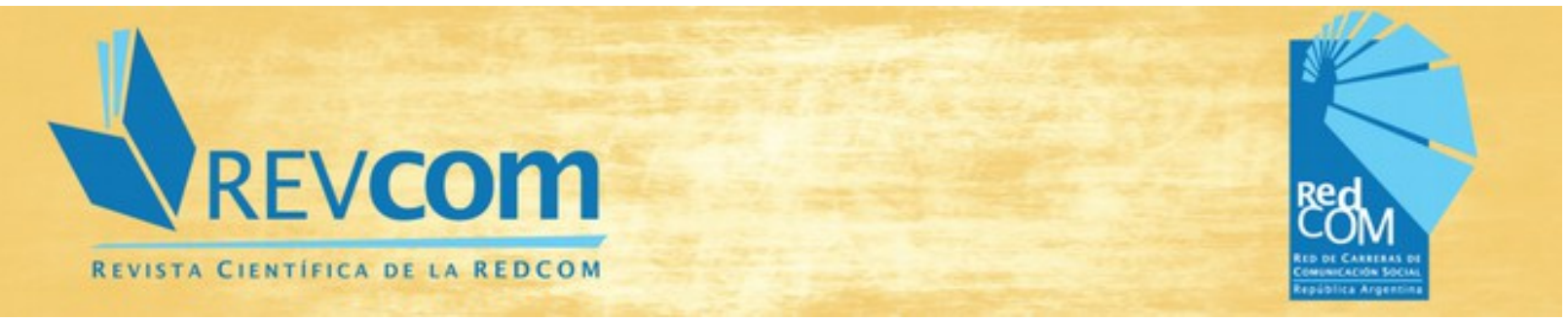

REVCOM | ISSN 2451-7836 | Año 4, \#8 | mayo de 2019 | Contribuciones | e013

así el estereotipo de la colombiana sensual. María Camila trabaja en una discoteque -que a ratos parece más bien un burdel- donde tiene una relación amorosa con el dueño en un momento del desarrollo del melodrama. Así, no es raro que se haga alusión en términos de imaginarios a la vinculación que se hace generalmente respecto a que las colombiana que migran a nuestro país se dedican al comercio sexual.

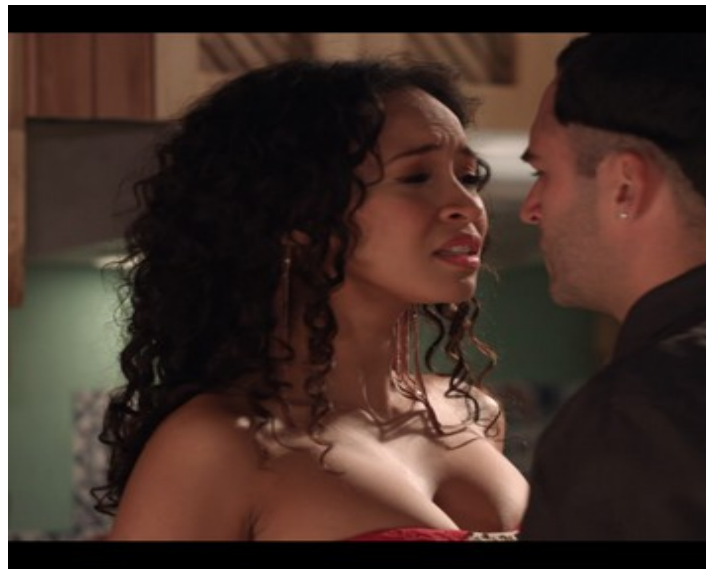

Imagen 4

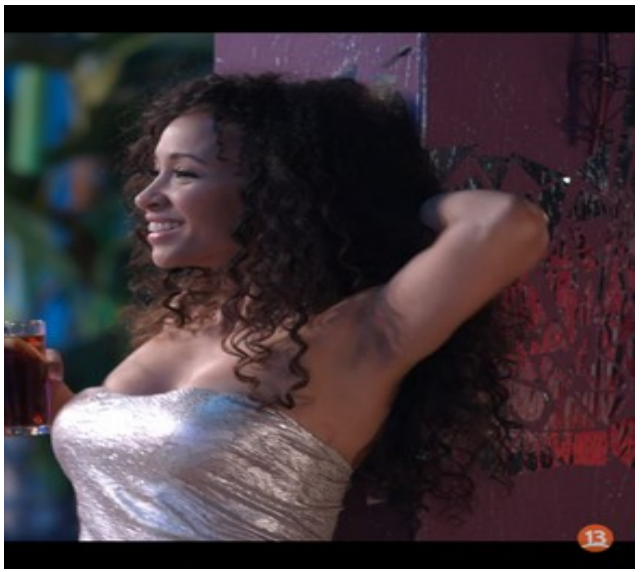

Imagen 5

Además, el recurso de sensualidad de María Camila aparece caracterizado como una forma de manipulación (Imagen 4,5 y 6) ya que se la significa como una seductora que usa sus atributos físicos para sacar partido y obtener beneficios. Presentamos a continuación el análisis (Tabla 4) donde se aprecia lo recién señalado.

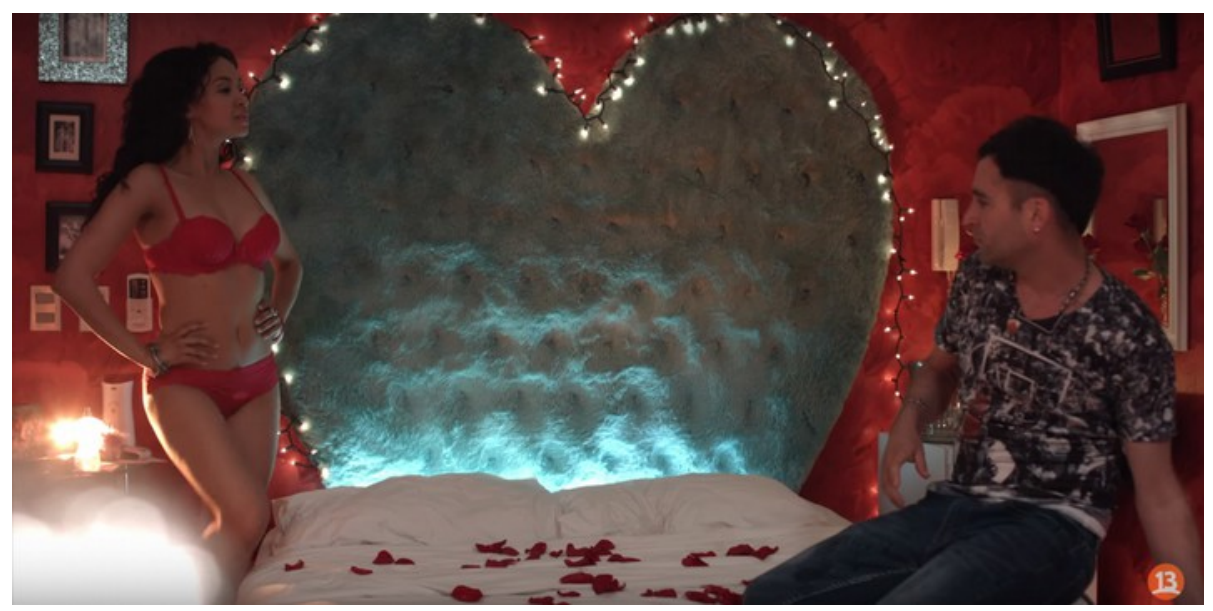

Imagen 6 
ANALISIS IMAGEN 6

\section{Nivel icónico}

Nivel iconográfico

La escenografía asociada al motel y a la pasión da cuenta de una posibilidad de intimidad física donde María Camila ofrece su cuerpo de manera seductora y juega con la excitación de Eric, para lograr algo que no puede por sus propios medios (ver nivel textual).

Así, la ambientación romántica está en realidad sujeta a un espacio de intercambio (una suerte de prostitución) donde se sexualiza a la colombiana y se le caracteriza como manipuladora.

Tabla 4. Análisis Imagen 6. Elaboración propia

Finalmente, el caso de Rosa María es bastante más sutil que los dos recién revisados, ya que no se encuentran escenas de semidesnudos en los que aparezca el personaje de la colombiana. Esto puede deberse a que la teleserie Te doy la vida fue exhibida en el horario de la tarde. Como sea, en ningún caso el personaje Rosa María aparece sexualizado a la manera que hasta aquí hemos revisado.

Lo que sí se evidencia en la caracterización de Rosa María es un recurso estético donde se acentúa una indumentaria y maquillaje que da cuenta de una preocupación por la imagen que es mayor al de todos los demás personajes femeninos de la teleserie. En este sentido se remite a un imaginario social que adhiere a los colombianos en general una alta preocupación por la estética y la apariencia física, dando cuenta de un estereotipo asociado a la vanidad y al erotismo. Así, Rosa María siempre aparece con ropa ceñida, vestidos, y otros atuendos que aparecen como vistosos o estéticamente llamativos en el contexto de la teleserie. Del mismo modo, el uso de recursos como un marcado maquillaje, accesorios llamativos (aros, carteras, joyas, etc.) y una vestimenta que aparece sugestiva en comparación con la de los demás personajes, dan cuenta de un imaginario donde se exacerba la importancia de la estética con 


\section{$\downarrow_{\text {REVCOm }}$ \\ REVISTA CIENTIFICA DE LA REDCOM}

REVCOM | ISSN 2451-7836 | Año 4, \#8 | mayo de 2019 | Contribuciones | e013

elementos de sensualidad, aunque sin caer en una sexualización, como en los dos casos anteriores.

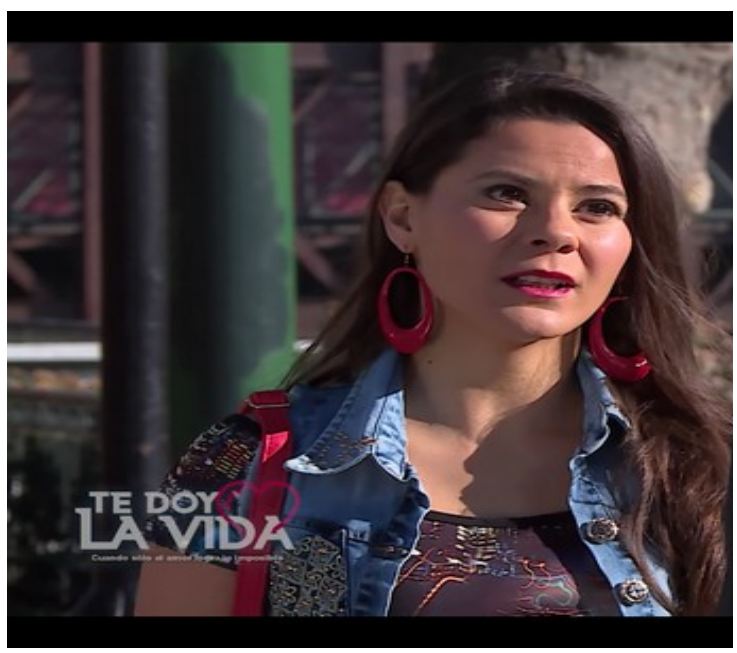

Imagen 7

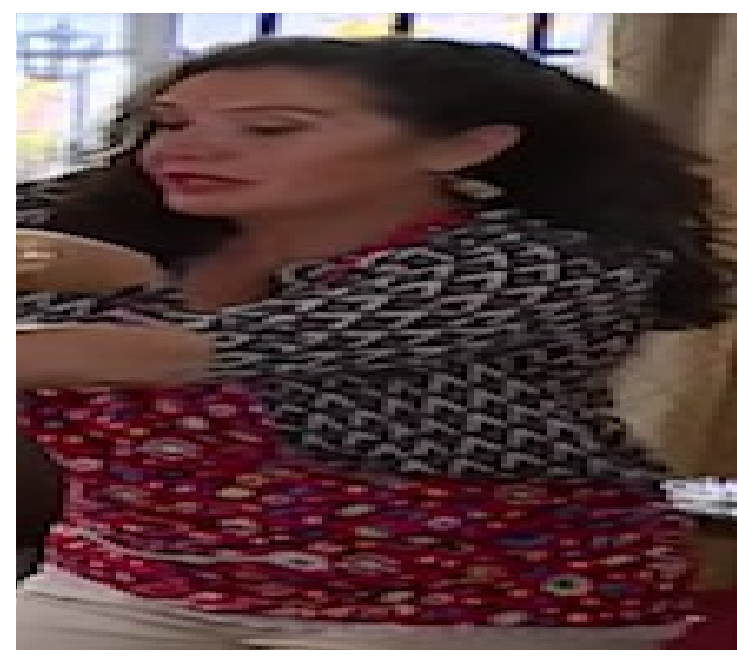

Imagen 8

\subsection{Antagonismo y rivalidad amorosa}

Retomamos aquí la definición de Aguilera (2015), quien nos recuerda que el melodrama o la teleserie -conceptos que hemos usado hasta aquí indistintamente- se centra en la vinculación entre el mundo privado y cotidiano con un fuerte énfasis de lo sentimental-amoroso, que se desarrolla entre la tensión del deseo y del impedimento, es decir, entre la concreción y no concreción del sentimiento amoroso y de las relaciones sentimentales.

Para el caso de los personajes Úrsula y Rosa María, esta dimensión sentimental de tensión se cumple cabalmente, ya que ambas están involucradas en una trama donde un sujeto masculino aparece frente a la disyuntiva de permanecer en la relación que mantienen con la inmigrante o de romper esta relación y pasar a otra relación con una chilena. De modo similar ocurre con María Camila, cuya relación con Darío se ve en entredicho por la llegada del grupo de fugadas frente a las que María Camila se siente amenazada, aunque a diferencia de los otros dos casos, Darío no deja a María Camila por alguna de las chilenas, sino por los celos y malas conductas de la propia María Camila. Así, las chilenas aparecen en las teleseries analizadas como agentes disruptivos del amor y que desencadenan el desamor para las mujeres migrantes. Esta narración melodramática la exponemos como secuencia en la tabla 5: 
REVCOM | ISSN 2451-7836 | Año 4, \#8 | mayo de 2019 | Contribuciones | e013

\begin{tabular}{|c|c|c|c|}
\hline $\begin{array}{l}\text { Descripción } \\
\text { Personaje }\end{array}$ & $\begin{array}{l}\text { Tiene relación } \\
\text { amorosa con: }\end{array}$ & $\begin{array}{l}\text { Aparece un agente } \\
\text { disruptivo: }\end{array}$ & Resultado: \\
\hline Úrsula & Antonio & Ema (mujer chilena) & $\begin{array}{l}\text { Ema se queda con } \\
\text { Antonio y Úrsula } \\
\text { vuelve a su país }\end{array}$ \\
\hline Rosa María & Samuel & $\begin{array}{l}\text { Gabriela (mujer } \\
\text { chilena) }\end{array}$ & $\begin{array}{l}\text { Gabriela se queda } \\
\text { con Samuel y Rosa } \\
\text { María tiene otra } \\
\text { pareja }\end{array}$ \\
\hline María Camila & Darío & $\begin{array}{l}\text { Las fugadas de la } \\
\text { cárcel ("las } \\
\text { preciosas") }\end{array}$ & $\begin{array}{l}\text { Darío deja a María } \\
\text { Camila y esta busca } \\
\text { nuevos rumbos }\end{array}$ \\
\hline
\end{tabular}

Tabla 5. Análisis de la narración en el vínculo amor-desamor. Elaboración propia

En este caso son las chilenas las que le quitan la pareja a las inmigrantes o las que se posicionan significacionalmente como la causa del desamor de las mujeres inmigrantes. Esto podría explicarse como un intento consciente por salir del cliché o el estereotipo que posiciona a las mujeres inmigrantes (sobre todo si son sensuales, como las que son objeto de este análisis) como capaces de seducir a hombres que ya tienen pareja.

Otra posibilidad -sea de manera consciente o no consciente- es que posicione la feminidad chilena como superior a la extranjera, y de ser este el caso estaríamos entonces frente a una construcción radical del imaginario de la identidad (las chilenas) que superarían a la alteridad (las inmigrantes), al menos en lo relativo al cumplimiento del deseo amoroso o sentimental.

Como sea, lo cierto es que en el aspecto figurativo e isotópico de la configuración significacional y narrativa de la mujer migrante (Imagen 9), esta aparece ligada a la figura del desamor, unido a las figuras de celos, rivalidad y despecho.

Imagen 9. Figuras e Isotopías asociadas a la mujer migrante 


\section{$\checkmark$ REVCOm \\ REVISTA CIENTIFICA DE LA REDCOM}

REVCOM | ISSN 2451-7836 | Año 4, \#8 | mayo de 2019 | Contribuciones | e013

A nivel actancial-narrativo, la dualidad amor-desamor se posiciona como uno de los componentes de análisis de la dimensión semio-discursiva del relato melodramático. Responde a un elemento central de la trama y del tratamiento narrativo de la mujer inmigrante en relación con otros personajes de la teleserie. Así, las inmigrantes aparecen finalmente como una oponente (Tabla 5) de otros actantes (chilenos o no migrantes), modalizadas por una aspiración (un querer) y por la incapacidad de llevar este deseo a una concreción efectiva (no poder).

\begin{tabular}{ll|l|l|}
\hline $\begin{array}{l}\text { Descripción } \\
\text { Personaje }\end{array}$ & $\begin{array}{l}\text { Objeto de valor en } \\
\text { disputa }\end{array}$ & Modalización & Ayudante/Oponente \\
\hline Ursula (Peruana) & Antonio (Amor) & Querer/No Poder & $\begin{array}{l}\text { Oponente de Ema } \\
\text { (Chilena) }\end{array}$ \\
\hline $\begin{array}{l}\text { Rosa María } \\
\text { (Colombiana) }\end{array}$ & Samuel (Amor) & Querer/No Poder & $\begin{array}{l}\text { Oponente Gabriela } \\
\text { (Chilena) }\end{array}$ \\
\hline $\begin{array}{l}\text { María Camila } \\
\text { (Colombiana) }\end{array}$ & Darío (Amor) & Querer/No Poder & $\begin{array}{l}\text { Oponente (“las } \\
\text { Preciosas", chilenas) }\end{array}$ \\
\hline
\end{tabular}

Tabla 6. Análisis de los componentes del nivel actancial-narrativo. Elaboración propia

\subsection{Victimización}

Finalmente, se visualiza a través del modelo de análisis propuesto un imaginario de la mujer migrante asociado a la victimización. El recurso discursivo-narrativo para posicionar este aspecto se asocia para el caso de los dos personajes colombianos (Rosa María y María Camila) a la presencia latente de un marido colombiano al que las protagonistas intentan evitar a toda costa. La mujer aparece caracterizada por una trama o una narrativa paralela que, si bien no es el centro de sus historias en las teleseries analizadas, sí recorre su identidad. Este elemento se refiere a que aquellos hombres (maridos o parejas) han ejercido algún tipo de violencia en el pasado de los personajes, lo que ha dejado secuelas o miedos latentes del que las migrantes no se pueden despojar, al menos ese es el caso de Rosa María y María Camila.

Resulta sugerente al respecto que, al mismo tiempo que el imaginario de la mujer migrante aparece como oponente frente a otras mujeres, estas también parecen tener sus propios oponentes. Al respecto, podría estar operando una forma de equilibrio en la 


\section{$\downarrow_{\text {REVCOM }}$ \\ REVISTA CIENTIFICA DE LA REDCOM}

REVCOM | ISSN 2451-7836 | Año 4, \#8 | mayo de 2019 | Contribuciones | e013

representación de la mujer migrante, puesto que por una parte se la significa como oponente (rival o victimaria) y por otra se le posiciona como víctima.

A modo de ejemplo, es reveladora una escena donde María Camila cuenta que al llegar a Chile (huyendo de su marido) conoce a otro hombre con el que tienen una relación, hasta que él comienza a abusar de ella y a violentarla físicamente. El caso de Rosa María es similar; mientras está en una relación con Samuel constantemente siente temor de que aparezca quien es su marido y de que le haga daño a Samuel. En estos dos casos aparece entonces la figura de un hombre que opera como victimario de las mujeres inmigrantes.

El caso de la migrante peruana (Úrsula) es algo distinto; la victimización que opera en este personaje no se relaciona con la presencia (latente o evidente) de una ex-pareja o un hombre que la victimiza, sino más bien como víctima de los sentimientos de Antonio hacia Ema que han minado la relación idílica que antes tenían. En esta tensión entre amor-desamor Úrsula planea quedar embarazada de Antonio para así poder mantener su relación y hacer que Antonio se olvide de Ema, sin embargo finalmente Úrsula pierde a su hijo producto de un aborto espontáneo. En el caso de Úrsula, la mujer migrante aparece representada entonces como víctima del desamor, y como víctima de la naturaleza en su condición de mujer. Pareciera ser que el desamor y el dolor por el hijo perdido aparece ligado a la condición misma de la mujer operando así un imaginario social que naturaliza el dolor y el sufrimiento en la mujer como condición esencialista del propio género.

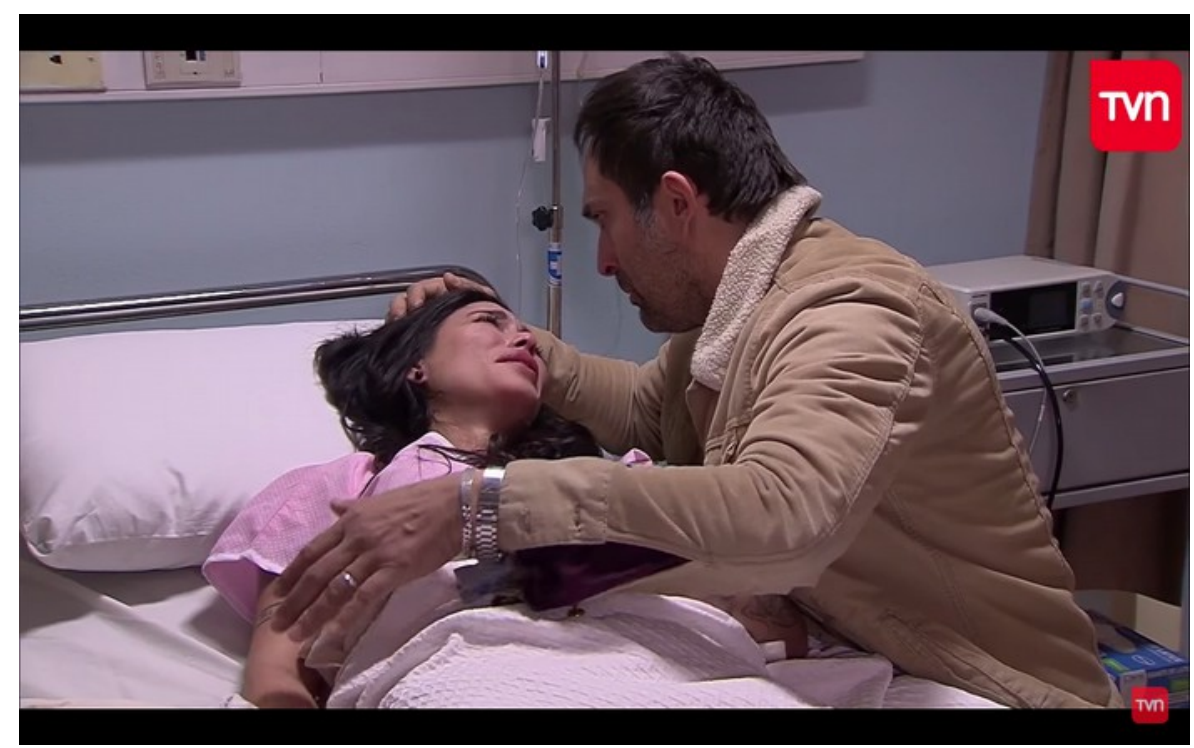

Imagen 10 
REVCOM | ISSN 2451-7836 | Año 4, \#8 | mayo de 2019 | Contribuciones | e013

\section{Consideraciones finales: ¿la teleserie como espacio de (inter)cultura?}

Los imaginarios sociales identificados como parte de la construcción social de la mujer migrante en las teleseries analizadas da cuenta de elementos socio-culturales e históricos que se actualizan en la telenovela, aunque igualmente aparecen singularidades referidas por ejemplo, a que en el material estudiado aparece una suerte de inversión de roles donde no es la mujer migrante la que se interpone en una relación, sino que son las chilenas quienes le quitan la pareja a las inmigrantes.

Estas dos dinámicas, donde los imaginarios aparecen como tributarios de elementos significacionales socio-históricos previamente establecidos, y al mismo tiempo, como articuladores de nuevas significaciones, o nuevos imaginarios, remite a la doble cualidad de los imaginarios sociales en cuanto elementos estructurantes y estructurados. Se aprecia una base dialéctica ineludible en relación a lo instituido y lo instituyente y posiciona el carácter contestatario que pueden tener los imaginarios sociales en relación a la constitución de nuevos imaginarios.

Todo esto aparece como relevante puesto que aquí se ha propuesto la díada identidad/alteridad como dos caras de una misma moneda; es decir, la identidad -el nosotrosno existe si no es por correspondencia o contradicción a un otros -la alteridad-. Así las cosas, las relaciones entre la sociedad chilena y los inmigrantes -la identidad y la alteridad- sería entonces una cuestión ineludiblemente intercultural que puede desarrollarse de forma armoniosa o disonante.

En este sentido Gallegos (2015) nos recuerda que lo intercultural no tiene que ver exclusivamente con lo indígena, que ha sido el énfasis otorgado en la sociedad chilena a propósito de pueblos originarios y particularmente el mapuche; lo intercultural estaría dado entonces por el contacto entre el Yo (identidad) y el Otro (alteridad) que se constituirían en términos diferenciadores; ya sean diferencias de género, urbanidad/ruralidad, etarias, o como en este caso, diferencias relativas al país de nacimiento, la condición de migrante, color de piel, acento, o las que conformen la idea de inmigrante.

Así, y en consideración de que en la telenovela aparecen elementos significacionales que apuntan en dirección contraria a los estereotipos sobre las mujeres inmigrantes ("las inmigrantes quitan maridos"), podría entonces la telenovela considerarse un espacio de intercultura o de identificación universal de la mujer ("todas las mujeres sufrimos desamor... 
REVCOM | ISSN 2451-7836 | Año 4, \#8 | mayo de 2019 | Contribuciones | e013

incluso las inmigrantes"), aunque sin embargo de esto es preciso mantener una perspectiva crítica de la significación y los imaginarios de sexualización, victimización y de rivalidad que sin duda estigmatiza y reproducen un estereotipo de la mujer migrante. En este sentido quedan abiertas las posibilidades de estudio de diversos productos culturales y sobre las formas en que estos reproducen imaginarios ya existentes o instauran nuevas formas de pensar los grupos marginados como los migrantes.

\section{REFERENCIAS BIBLIOGRÁFICAS}

Aguilera, R. (2015). Chilenas y su identificación con los personajes femeninos de Pasión de Gavilanes. Cuadernos.info,36, 207-218. DOI: 10.7764/cdi.36.601.

Alarcón, P. (2002). El acto sexual es comer: descripción lingüístico-cognitiva. Revista de Lingüística Teórica y Aplicada, 40, 7-24.

Baczko, B. (2005). Los imaginarios sociales: memorias y esperanzas colectivas. Buenos Aires: Nueva Visión.

Barthes, R. (1964). Rhétorique de l'image. RevistaCommunications, 4, 40 -51. DOI: 10.3406/comm.1964.1027.

Berger, P. \&Luckmann, T. (2001). La construcción social de la realidad. 17ª edición. Buenos Aires: Amorrortu.

Castoriadis, C. (2007). La institución imaginaria de la sociedad.Buenos Aires: Tusquets.

Charaudeau, P. (2003). El discurso de la información. Barcelona: Gedisa.

Courtes, J. (1980). Introducción a la semiótica narrativa y discursiva. Metodología y aplicación. Buenos Aires: Librería Hachete.

Curran, J. (2002). Medios de comunicación y poder en una sociedad democrática. Barcelona: Editorial Hacer.

Fontanille, J. (2001). Semiótica del discurso.Lima:F.C.E. y Fondo de Desarrollo Editorial Universidad de Lima eds.

Fontanille, J. (2004). "Sémiotique des textes et des discours". En Dictionnaire des méthodes qualitatives en sciences humaines (pp. 251-253). Paris:Armand Colin.

Fontanille, J. (2009). "Sémiotique de l'École de Paris". En Vocabulaire des études sémiotiques et sémiologiques (pp.43-48). Paris: Presses Universitaires de France-Comté.

Fuenzalida, V. (2012). Una interpretación socio-semiótica de la representación televisiva de la política. La oportunidad de la TV digital. Cuadernos de Información, 30, 83-96.DOI: 10.7764/cdi.30.428

Fuenzaliza, V; Corro, P \& Mujica, C. (2009). Melodrama, subjetividad e historia en el cine y televisión chilenos de los 90. Santiago: Eds. Universidad Católica de Chile. 
REVCOM | ISSN 2451-7836 | Año 4, \#8 | mayo de 2019 | Contribuciones | e013

Gallegos, E. (2015). "Semiótica de la alteridad y/o alteridades semióticas. Hacia un modelo semiodiscursivo para el estudio de la identidad/alteridad". En Signatura (pp.81-102). Temuco: Ediciones Universidad de La Frontera.

Giroud, J.C. \&Panier, L. (1988). Semiótica. Navarra: Editorial Verbo Divino.

Greimas, A.J. (1973). Un problème de sémiotique narrative: les objets de valeur. Langages. 8e année. 31. 13-35. DOI : 10.3406/lgge.1973.2233

Gubern, R. (1994).La mirada opulenta.3ª Edición. Barcelona: Gustavo Gili.

Hall, S. (1996). "Encoding/decoding”. EnCulture, Media, Language. Working Papers in Cultural Studies, 1972-79 (pp.128-138). Londres: Routledge \& The CCCS University of Birmingham.

Hall. S. (2010).“Etnicidad: identidad y diferencia”. En: EnSin garantías: Trayectorias y problemáticas en estudios culturales (pp. 339-348). Colombia: Envión editores.

Landowski, E. (1993). La sociedad figurada. Ensayos de sociosemiótica. Buenos Aires: Fondo de Cultura Económica.

Martín-Barbero, J. (1991). De los medios a las mediaciones. Comunicación, cultura y hegemonía. $2^{a}$ edición. México: Gustavo Gili.

Mattelart, A. \&Mattelart, M. (1997). Historias de las teorías de la comunicación. Buenos Aires: Paidós.

Mazziotti, Nora. (2006). Telenovela, industria y prácticas sociales. Bogotá:Grupo Editorial Norma.

McQuail, D. (2000). Introducción a la teoría de la comunicación de masas. $3^{a}$ edición. Barcelona: Paidós Comunicación.

Rojas, N. \& Silva, C. (2016). La migración en Chile: Breve reporte y caracterización. Madrid: OBIMID.

Thompson, J. (1998). Los media y la modernidad. Barcelona: Paidós.

Tijoux, M.E. \& Palominos, S. (2015). Aproximaciones teóricas para el estudio de procesos de racialización y sexualización en los fenómenos migratorios de Chile. Revista Polis. 42/14.247-275. DOI: 10.4067/S0718-65682015000300012

Wolf, M. (1987). La investigación de la comunicación de masas. Barcelona: Paidós. 